\title{
Metatarsophalangeal Joint 3
}

National Cancer Institute

\section{Source}

National Cancer Institute. Metatarsophalangeal/oint 3. NCI Thesaurus. Code C102323.

A condyloid synovial joint within the third digit of the foot connecting metatarsal with the proximal phalanx. 